\title{
Validity and reliability of scales on intrapersonal, interpersonal and environmental factors associated with physical activity in Brazilian secondary students
}

\section{Validade e fidedignidade de escalas sobre fatores intrapessoais, interpessoais e ambientais associados à atividade física em escolares brasileiros do ensino fundamental}

\author{
Valter Cordeiro Barbosa Filho $0^{1,2,3}$ \\ Cassiano Ricardo Rech ${ }^{1}$ \\ Jorge Mota ${ }^{2}$ \\ José Cazuza de Farias Júnior ${ }^{4}$ \\ Adair da Silva Lopes ${ }^{1}$
}

Abstract - This study aimed to examine the validity and reliability of scales of intrapersonal, interpersonal, and environmental factors associated with physical activity (PA) in secondary students. Two cross-sectional studies were conducted with students in 7 th to 9 th grades form secondary schools in order to test the validity, internal consistency $(\mathrm{n}=$ $1,178,51.4 \%$ were boys), and test-retest reproducibility ( $n=194,56.2 \%$ were boys) of the instrument. Factors associated with PA (attitude, self-efficacy, social support of friends, parents and the school's teachers, as well as the perceived neighborhood environment and perceived school environment) were measured. The confirmatory factor analysis and Spearman correlation between the scales and the weekly time spent in moderateto-vigorous PA (measured by questionnaire) were applied to test the construct validity. For reliability, the Cronbach's $\alpha$ (internal consistency), composite reliability (CR) and intraclass correlation coefficient (ICC for test-retest reproducibility) were applied. The confirmatory factorial analysis showed five one-dimensional and two two-dimensional (self-efficacy and perceived environment) scales, with factor loadings ranging from 0.46 to 0.85 . Significant and positive correlations between almost all scale scores and moderateto-vigorous PA ( $\mathrm{p}<0.05)$ were found. The Cronbach's $\alpha$ and CR were greater than 0.70 in almost all scales (except perceived school environment, $\alpha$ and CR of 0.61) and the ICC ranged from 0.62 (parental social support) to 0.70 (self-efficacy). In conclusion, the scales showed acceptable validity and reliability and can be used for measuring of PA correlates in elementary students.

Key words: Motor activity; Reproducibility of results, Psychometrics; Psychosocial aspects; Validity tests.

Resumo - Este estudo analisou a validade e a fidedignidade de escalas de fatores intrapessoais, interpessoais e ambientais associados à atividade física ( $A F)$ em escolares do ensino fundamental. Estudos transversais incluíram escolares dos $7^{\circ}$ ao $9^{\circ}$ anos para análises de validade e consistência interna ( $n=1.178,51,4 \%$ meninos), e reprodutibilidade teste-reteste ( $n=194,56,2 \%$ meninos) do instrumento. Atitude, autoeficácia, apoio social dos amigos, pais e professores da escola, e o ambiente percebido do bairro e da escola relacionados à AF foram avaliados. A análise fatorial confirmatória e a correlação de Spearman entre os escores das escalas e o tempo semanal em AF moderada a vigorosa foram aplicadas para testar a validade de constructo das escalas. Utilizou- se $o \alpha$ de Cronbach e o indice de fidedignidade combinada (IFC) para avaliar a consistência interna, e o coeficiente de correlação intra-classe (CCI) para a reprodutibilidade teste-reteste. $A$ análise fatorial confirmatória indicou cinco escalas unidimensionais e duas bi-dimensionais (autoeficácia e ambiente percebido para $A F$ ), com ajustes de modelo adequados e cargas fatoriais de 0.46 a 0.85. Houve correlações significativas entre os escores de quase todas as escalas e AF moderada a vigorosa $(p<0,05)$. O a e o IFC foram maiores de $0.70 \mathrm{em}$ quase todas as escalas (exceto ambiente percebido da escola, a e IFC de 0.61) e o CCI variou de 0.62 (apoio social dos pais para AF) a 0.70 (autoeficácia para AF). Em conclusão, as escalas apresentaram validade e fidedignidade aceitáveis e pode ser utilizado na mensuração de fatores associados à AF em escolares do ensino fundamental.

Palavras-chave: Atividade motora; Fatores psicossociais; Reprodutibilidade dos testes; Psicometria; Validade de testes.
1 Federal University of Santa Catarina. Department of Physical Education. Research Centre in Physical Activity and Health. Florianopolis, SC. Brazil.

2 University of Porto. Faculty of Sport. Research Centre in Physical Activity, Health and Leisure. Porto, Portugal.

3 Federal University of Ceara. Research Centre in Physical Activity and Health in School. Institute of Physical Education and Sports. Fortaleza, CE. Brazil.

4 Federal University of Paraiba. Research and Study Groups in Epidemiology of Physical Activity. João Pessoa, PB. Brazil.

Received: 12 October 2015 Accepted: 25 January 2016 


\section{INTRODUCTION}

Identifying the factors that can influence people's choices regarding physical activity (PA) has been considered an important subject in PA studies ${ }^{1}$. Different theoretical approaches (e.g., socio-ecological or socio-cognitive theories) have been used to understand these factors and how they can interfere in PA practice in the population, including with young people ${ }^{2-4}$. The socio-ecological theory emphasizes that PA may be influenced by interpersonal (e.g., self-efficacy), interpersonal (e.g., social support) and environmental (e.g., neighborhood environment) factors ${ }^{2}$. Although this theory does not define or establish which constructs should be measured, some instruments of the factors associated with $\mathrm{PA}^{3,5-7}$ have been based on the socio-ecological theory.

An instrument was developed and validated with scales of intrapersonal (attitude and self-efficacy), interpersonal (social support of parents and friends) and environmental (perceived neighborhood environment) factors associated with PA, considering a sample of students from public and private high schools (aged 14-19 years) in Joao Pessoa, Brazil ${ }^{5}$. All scales had adequate internal consistency (Cronbach's $\alpha$ from 0.69 and 0.90 ) and test-retest reproducibility (intraclass correlation coefficient (ICC) from 0.67 and 0.91$)^{5}$. However, the factorial confirmation of these scales in secondary schools has not been evaluated. Instruments used in young people without information on validity and reliability have been recurrent in the literature ${ }^{2,4,8,9}$. Moreover, the instrument previously mentioned ${ }^{5}$ and other instruments for young people $5^{5,10,11}$ have not included aspects of the school environment (facilities/resources and encouragement for school teachers) that may be associated with PA practice. Evaluating the perception of the students on the PA-related school environment is important because this context focuses on PA public policies in Brazil ${ }^{12}$ and can contribute to an active lifestyle among young people ${ }^{13}$. Filling in these gaps is important to indicate adequate scales for measuring factors associated with PA among Brazilian secondary students in order to guide studies on PA correlates and determinants, as well as potential mediators of the intervention effect in PA among young people $\mathrm{e}^{1,4,8,13}$.

Therefore, this study aimed to analyze the validity and reliability of scales for measuring intrapersonal, interpersonal and environmental factors associated with PA in Brazilian secondary students.

\section{METHOD}

The instrument used in this study was developed in order to measure factors associated with PA in an intervention study that aimed at active and healthy lifestyle promotion among students in Fortaleza, northeastern Brazil - the "Fortaleça sua Saúde" program. A detailed description of the population of interest, sampling and intervention program is in the trial record (ClinicalTrials.Gov-NCT02439827). 


\section{Population and study sample}

- Study 1 - validity and internal consistency (reliability)

One sample was evaluated in order to analyze the validity and internal consistency (reliability) of the instrument. For this purpose, 1,272 students from 40 grade 7-9 classes in all six public secondary full-time schools (all were enrolled in the national program called Programa Saúde na Escola) in Fortaleza were eligible; they were invited to participate in the "Fortaleça sua Saúde" program. Of these, 87 were not present at school after two/ three days of data collection, four students refused to participate and 11 questionnaires were excluded due many unanswered questions. A total of 1,178 students had valid data. This sample size was adequate for estimating validity and reliability parameters, considering the rate of 20 individuals for each item of the instrument (56 initial items x $20=$ at least 1,120 subjects) ${ }^{14}$.

- Study 2 - Test-retest reproducibility (reliability)

Another sample was used to verify the test-retest reproducibility of the instrument. For this, two public schools in Fortaleza, independent of the schools in Study 1, were intentionally selected. Students from the 12 grade 7-9 classes were eligible. In total, 194 students contributed test-retest data. This sample allows for the identification of ICC greater than 0.20 as statistically significant $(\alpha=0.05)$ and $80 \%$ power $(\beta=0.20)$ with two instrument applications.

\section{Instruments}

The instrument analyzed in this study was proposed for evaluating factors associated with PA in adolescents aged 14-19 years ${ }^{5}$. The original instrument consisted of five PA-related scales: attitude, self-efficacy, parental social support, social support from friends and perceived neighborhood environment. The attitude scale included five items regarding affective and instrumental aspects of attitude related to PA practice, considering contrasting adjectives: safe-unsafe, fun-boring, important-negligible, health-harmful, good-bad (see instrument in Supplementary Material). Other scales had the response options in a four-point Likert scale. The self-efficacy scale included 13 items (ranging from 1 "strongly disagree" to 4 "strongly agree") and evaluated the students' perceptions of the ability to practice PA in adverse situations. The scales of social support of friends and parents included six items each (ranging from 1 "never" to 4 "always") and evaluated the students' perceptions of the frequency with which these social members stimulate PA practice for the students. The perceived environment scale included 14 items (ranging from 1 "strongly disagree" to 4 "strongly agree") on the students' perceptions of PA-related attributes (i.e., security, infrastructure, and access and attractiveness related to PA) in the neighborhoods where the student lived ${ }^{5}$.

All items from the original instrument ${ }^{5}$ were considered because the factorial construct in could be different in secondary students compared to in high school students. Two new scales were included: social support 
of the school's teachers and perceived school environment. Two reasons justify the inclusion of theses scales: 1) to evaluate potential variables previously highlighted as important PA predictors in youth ${ }^{3,13,15}$ and 2) school aspects may explain the effectiveness of the intervention program to promote $\mathrm{PA}^{2,4}$. The support of the school's teachers scale included six items (ranging from 1 "never" to 4 "always") and was built with the same structure of the social support scales. The school environment scale (six items, with response options ranging from 1 "strongly disagree" to 4 "strongly agree") considered the students' perception on aspects from the school environment that are related to PA practice (availability and access to PA equipment during breaks, conditions of PA sites, encouraging PA in physical education classes) and were highlighted in a systematic review ${ }^{13}$.

Gender, age, father and mother's schooling, and weekly time spent in moderate-to-vigorous PA (MVPA) were measured (the categories of the variables were in Table 1). Father and mother's schooling were evaluated based on the Brazilian Association of Research Companies methodology ${ }^{16}$. We used a previously validated list of $24 \mathrm{MVPA}^{17}$. Students reported the weekly frequency and duration of each PA that they performed in the previous week. Thus, we estimated the weekly time in MVPA.

\section{Procedures}

- Study 1 - Validity and internal consistency (reliability)

Evaluators previously trained in theoretical explanations and practical simulations administered the questionnaires. The questionnaire was filled out by students in the classroom, without the presence of teachers. Prior to administration, the evaluators provided instructions and read each question aloud. Then, the students answered the questions. Data collection was conducted in July 2014.

- Study 2 - Test-retest reproducibility (reliability)

The above-mentioned protocol was also used during the test-retest data collections. Data collection was applied (test) and repeated (retest) at an interval of 15 days. In the first application, students received the instrument in an envelope to complete. In the second application, the same procedure was carried out. Data collections were conducted in June 2014.

\section{Data analysis}

We used mean, standard deviation, and frequency for a description of the sample characteristics. All analyses were performed using the software SPSS 21.0 (SPSS, Inc., Chicago, IL) with a significance level of 5\%.

- Study 1 - Validity and internal consistency (reliability)

A confirmatory factor analysis was performed with the software AMOS 21.0 (SPSS, Inc., Chicago, IL), using the method of Maximum Likelihood Estimation. The parameters suggested by Hair et al. ${ }^{14}$ were used to consider the goodness-of-fit model: 1) comparative fit index - CFI > 
$0.90,2)$ non-normed fit index $-\mathrm{NFI}>0.95,3)$ root mean square error of approximation - RMSEA $<0.05$ for a good fit and an upper value of 0.08 for a reasonable fit, and 4) $\mathrm{X}^{2}$ goodness-of-fit test $\mathrm{p}$-value $>0.05$ to indicate whether the residuals were significant or the ratio between CMIN $\left(\mathrm{X}^{2}\right)$ and degree of freedom $(\mathrm{CMIN} / \mathrm{DF})<11$. Adjustments to achieve a better-fitted model were conducted based on the Modification Index (MI) and values of standardized residuals (recommended when they stay higher than \pm 2.58$)^{18}$. Additionally, items were included to the final scale whether they had factor loadings greater than or equal to $0.40^{14}$. When the factorial structure of a scale was not confirmed during the initial confirmatory factor analysis, we performed an exploratory factor analysis in order to find a factorial structure of the scale in this sample. Then, we conducted a second confirmatory factor analysis ${ }^{18}$.

Construct validity was assessed using Spearman's correlation coefficient (rho) between the scale scores and the weekly time in $\mathrm{MVPA}^{2}$. Items where higher values represent conditions that were less favorable to PA practice had their values reversed before the sum of the scale scores. Considering that PA can be influenced by multiple aspects ${ }^{1}$, this analysis did not intend to show perfect correlation between scale scores and MVPA, but indicate the direction of this association.

Internal consistency was tested using Cronbach's Alpha $(\alpha)$ and composite reliability (CF, http://www.thestatisticalmind.com/calculators/ comprel/comprel.htm). Values $\alpha$ and $\mathrm{CF} \geq 0.70$ were adequate. However, values ranging from 0.60 to 0.69 were considered substantial because scales tend to have limited reliability among young people ${ }^{2,19,20}$.

- Study 2 - Test-retest reproducibility (reliability)

Test-retest reliability was assessed using the ICC with a confidence interval of $95 \%$ [95\% CI]) between test-retest measurements. ICC values $\geq 0.70$ were considered adequate and values from 0.60 to 0.69 were considered substantial ${ }^{2,19,20}$.

\section{Ethical Considerations}

Parents/guardians of the students authorized participation in this study by signing the informed consent. The National Research Ethics System (protocol No. 17366313.9.0000.0121) Federal University of Santa Catarina) approved this research project.

\section{RESULTS}

\section{Characteristics of samples}

There was a higher prevalence of boys (51.4\% and 56.2\%), aged 13 and 14 years (57.0\% and 52.3\%) and students whom fathers (42.0\% and $49.7 \%)$ and mothers (44.8\% and $42.4 \%$ ) had incomplete secondary education in the samples of Studies 1 and 2, respectively. No statistically significant difference between samples was found for these variables $(p<0.05)$. A 
sample of test-retest reproducibility (Study 2) showed a higher proportion of sufficiently active students ( $47.3 \%$ versus $55.2 \%$; $p<0.05$ ).

Table 1. Characteristics of the study samples. Fortaleza, Brazil (2014).

\begin{tabular}{|c|c|c|c|c|c|c|}
\hline \multirow[t]{2}{*}{ Descriptive Variables } & \multicolumn{2}{|c|}{$\begin{array}{l}\text { Sample of validation } \\
\text { and internal consistency } \\
\text { analyzes }(n=1,178)\end{array}$} & \multicolumn{2}{|c|}{$\begin{array}{l}\text { Sample of test-re- } \\
\text { test reproducibility } \\
\text { analyzes }(n=194)\end{array}$} & \multirow[t]{2}{*}{$x^{2}$} & \multirow[t]{2}{*}{$p$} \\
\hline & $\mathrm{n}$ & $\%$ & $\mathrm{n}$ & $\%$ & & \\
\hline Gender & & & & & 1.55 & 0.212 \\
\hline Boys & 605 & 51.4 & 109 & 56.2 & & \\
\hline Girls & 573 & 48.6 & 85 & 43.8 & & \\
\hline Age groups (years) & & & & & 7.90 & 0.066 \\
\hline $11-12$ & 246 & 20.9 & 34 & 17.6 & & \\
\hline $13-14$ & 672 & 57.0 & 101 & 52.3 & & \\
\hline 15 & 157 & 13.3 & 40 & 20.7 & & \\
\hline 16 or more & 103 & 8.7 & 18 & 9.3 & & \\
\hline Grades & & & & & 2.01 & 0.366 \\
\hline $7^{\text {th }}$ & 491 & 41.7 & 71 & 36.6 & & \\
\hline $8^{\text {th }}$ & 423 & 35.9 & 73 & 37.6 & & \\
\hline $9^{\text {th }}$ & 264 & 22.4 & 50 & 25.8 & & \\
\hline Father's schooling & & & & & 3.38 & 0.066 \\
\hline Primary incomplete & 114 & 9.7 & 15 & 8.8 & & \\
\hline Secondary incomplete & 458 & 38.9 & 52 & 30.4 & & \\
\hline High school incomplete & 495 & 42.0 & 85 & 49.7 & & \\
\hline High school complete or higher & 111 & 9.7 & 19 & 11.1 & & \\
\hline Mather's schooling & & & & & 0.2 & 0.902 \\
\hline Primary incomplete & 100 & 8.5 & 22 & 12.0 & & \\
\hline Secondary incomplete & 478 & 40.6 & 68 & 37.0 & & \\
\hline High school incomplete & 528 & 44.8 & 78 & 42.4 & & \\
\hline High school complete or higher & 72 & 6.1 & 16 & 8.7 & & \\
\hline PA level & & & & & 4.15 & 0.042 \\
\hline $\begin{array}{l}\text { Insufficiently active (<300 } \\
\text { min./wk.) }\end{array}$ & 557 & 47.3 & 106 & 55.2 & & \\
\hline $\begin{array}{l}\text { Sufficiently active ( } \geq 300 \mathrm{~min} . / \\
\text { wk.) }\end{array}$ & 621 & 52.7 & 86 & 44.8 & & \\
\hline
\end{tabular}

$\mathrm{PA}=$ physical activity. Min./wk. $=$ minutes per week. $\mathrm{X}^{2}=$ Chi-square test and its $\mathrm{p}$-value.

\section{Study 1 - Validity and reliability}

- Confirmatory factor analysis

A fitted model was found for the scales of attitude (five items) and support of parents (six items) with all initial items. All items showed factor loadings higher than 0.50 (Figure 1 and Table 2).

The self-efficacy scale had a two-factor structure, labeled with "individual and social barriers" and "resources to PA practice". The initial model showed inadequate model fit parameters (see supplementary material 1 ). Two items (2f and $2 \mathrm{~g}$ ) from the first factor and three items ( $3 \mathrm{~d}, 3 \mathrm{e}$, and 3f) from the second factor were excluded because they had factor loadings lower than 0.40 , elevated standardized residuals and/or high covariance with other items (see Figure 1). The exclusion of these items generated a 
Scales or Intrapersonal Variables

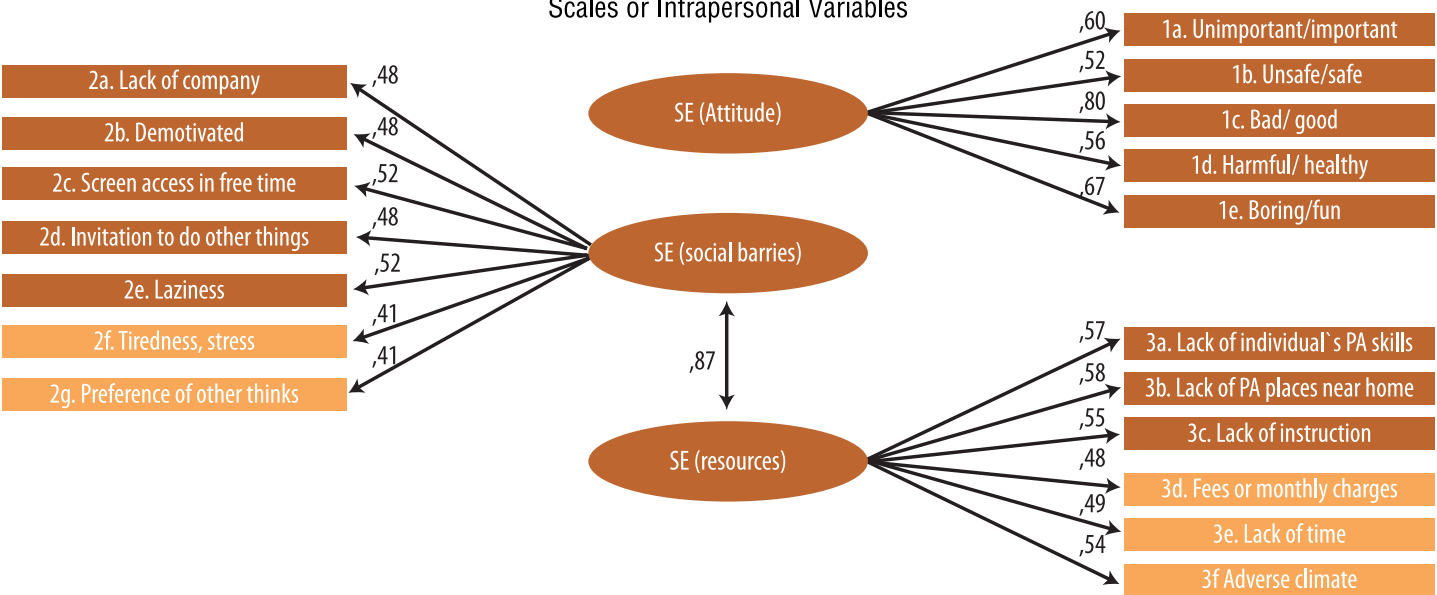

Scales or Interpersonal Variables

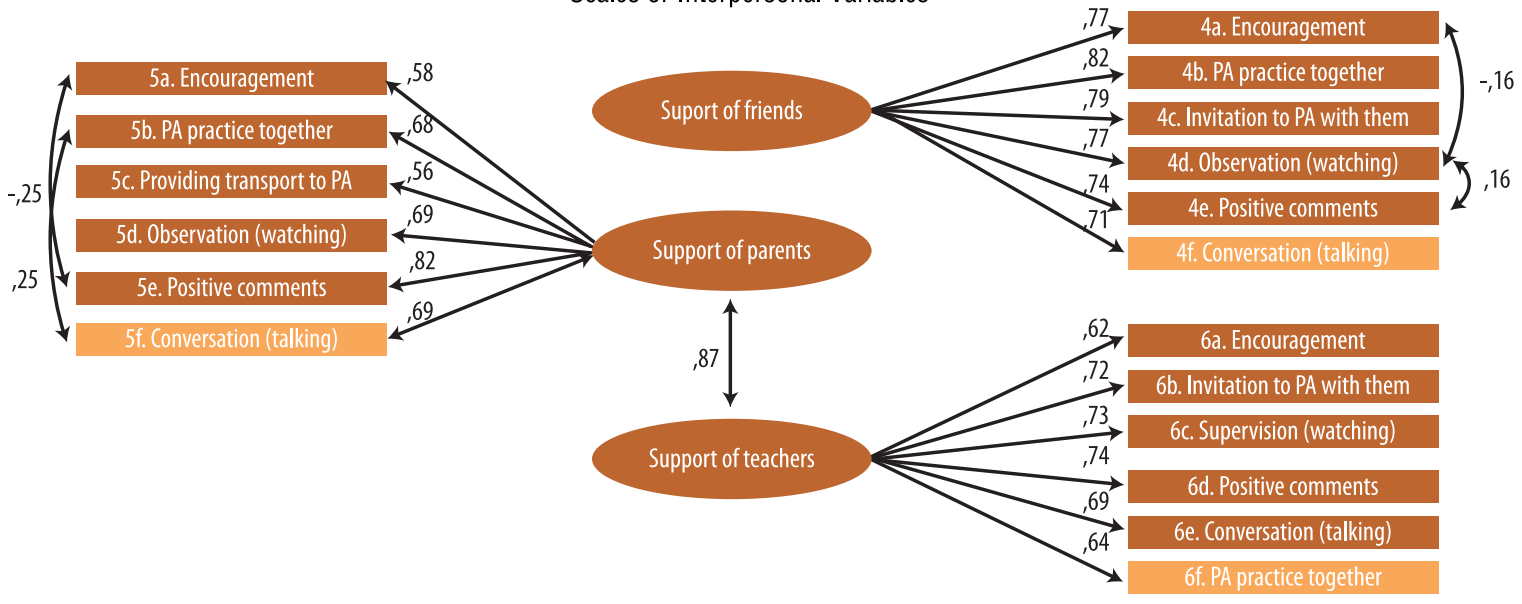

Scales of Perceived Environment Variables

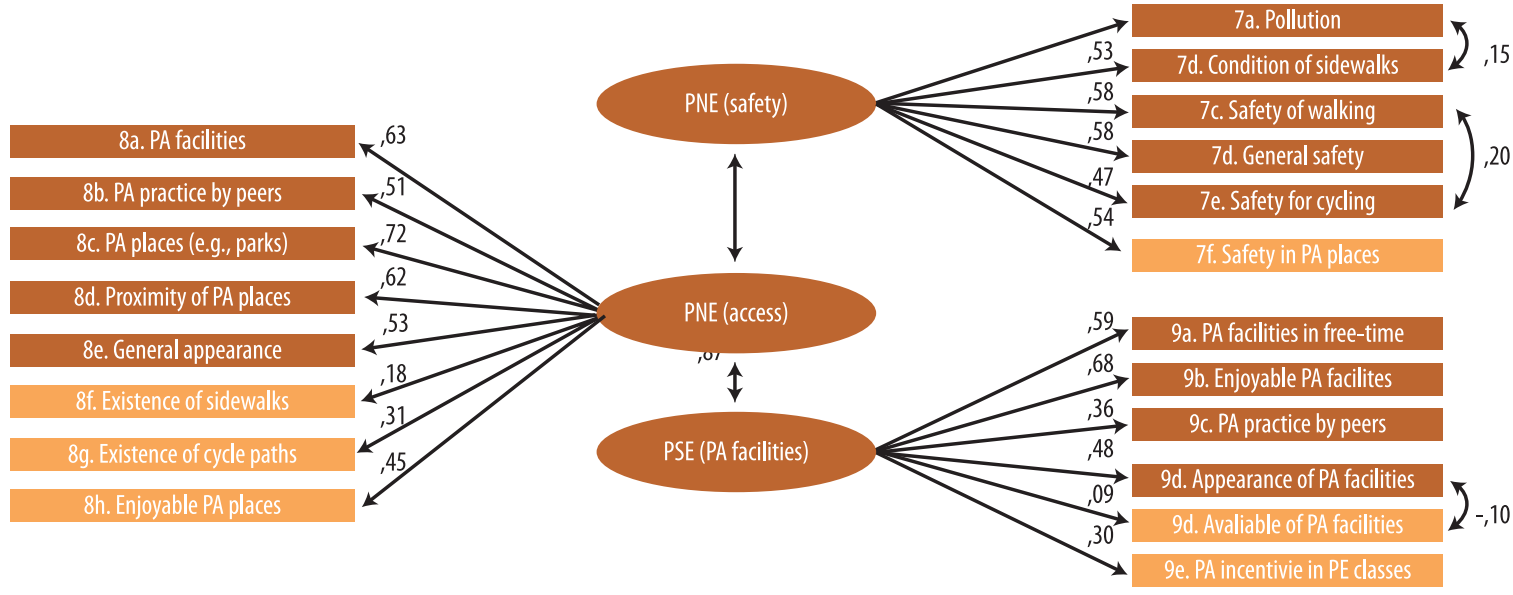

Figure 1. Confirmatory factor analyses of the initial scales of intrapersonal, interpersonal, and environmental physical activity variables among students. Fortaleza, Brazil (2014).

Note: Grayed out items were omitted during model revision. The overall goodness-of-fit of the models is provided in Supplementary Material 1. PA: physical activity; PNE (access): perceived neighborhood environment (access to PA facilities); PNE (safety): perceived neighborhood environment (safety and general state of maintenance); PSE (PA facilities): perceived school environment (physical activity facilities); PE: Physical Education; SE (social barriers): self-efficacy (individual and social barriers); SE (resources): self-efficacy (resources to physical activity practice). 
better-fitted model, and the included items had factor loadings ranging from 0.46 to 0.63 (see Table 2).

The support of friends was confirmed with five items, all with factor loadings from 0.76 to 0.85 . A better-fitted model for support of friends was obtained with the exclusion of one item (4f) and the inclusion of the correlation between the errors of three items (see Figure 1 and Table 2). In the scale of support of the school's teachers, a better-fitted model was obtained excluding one item (6f, see Supplementary Material 1 and Table 2). The factor loadings of the five remaining items ranged from 0.62 to 0.77 .

The initial confirmatory factor analysis indicated that the 14 items of the perceived neighborhood environment scale were not structured into three factors as in the original instrument. An exploratory analysis showed that this scale had a bi-factorial structure. This structure was assessed with a confirmatory factor analysis and the factors were labeled "safety and general state of maintenance" and "access to PA facilities" (Figure 1). One item in the first factor and three items from the second factors were excluded because they had low factor loading $(<0.40)$ and elevated standardized residuals ( $>2.58$, see Supplementary Material 1). Correlations between the errors of two items (Figure 1) from the "safety and general state of maintenance" were included to obtain a better-fitted model. The factor loading of the items ranged from 0.49 to 0.74 .

Table 2. Confirmatory factor analyses and reliability parameters of revised scales of intrapersonal, interpersonal, and environmental physical activity variables among students. Fortaleza, Brazil (2014).

\begin{tabular}{|c|c|c|c|c|c|c|c|c|}
\hline \multirow{3}{*}{$\begin{array}{l}\text { Scales ( } \mathrm{n} \text { items and \% of variance } \\
\text { explained by these items) }\end{array}$} & \multirow{3}{*}{ Mean (SD) } & \multicolumn{3}{|c|}{ Validity (Confirmatory Factorial Analysis) } & \multicolumn{4}{|c|}{ Reliability } \\
\hline & & \multicolumn{2}{|c|}{ Factor loading } & \multirow{2}{*}{ Parameters of model fit } & \multirow{2}{*}{$\alpha^{*}$} & \multirow{2}{*}{$\mathrm{CR}$} & \multirow{2}{*}{ ICC } & \multirow{2}{*}{$95 \% \mathrm{Cl}$} \\
\hline & & 1 & 2 & & & & & \\
\hline \multicolumn{9}{|l|}{ Scales of Intrapersonal Variables } \\
\hline $\begin{array}{l}\text { Attitude regarding engaging in PA ( } 5 \\
\text { items, } 52.7 \% \text { ) }\end{array}$ & $15.91(2.51)$ & - & - & \multirow{6}{*}{$\begin{array}{c}\mathrm{X}^{2}(\mathrm{df}=4)=6,34, \mathrm{p}=0.17 \\
\mathrm{CMIN} / \mathrm{DF}=1,58 \\
\mathrm{CFI}=0.99 ; \mathrm{NFI}=0.99 \\
\mathrm{RMSEA}=0.022(90 \% \mathrm{Cl} \\
0.000 ; 0.053)\end{array}$} & 0.77 & 0.77 & 0.62 & $0.56 ; 0.68$ \\
\hline 1a.Unimportant/important & $3.27(0.79)$ & 0.60 & - & & 0.73 & & 0.72 & $0.62 ; 0.83$ \\
\hline 1b. Unsafe/safe & $2.99(0.67)$ & 0.52 & - & & 0.75 & & 0.63 & $0.54 ; 0.70$ \\
\hline 1c. Bad/good & $3.26(0.70)$ & 0.80 & - & & 0.70 & & 0.58 & $0.49 ; 0.66$ \\
\hline 1d. Harmful/healthy & $3.32(0.57)$ & 0.56 & - & & 0.75 & & 0.65 & $0.56 ; 0.71$ \\
\hline 1e. Boring/fun & $3.07(0.75)$ & 0.67 & - & & 0.73 & & 0.59 & $0.51 ; 0.67$ \\
\hline $\begin{array}{l}\text { Perception of self-efficacy regarding } \\
\text { engaging in PA (8 items, } 47.2 \% \text { ) }\end{array}$ & $21.03(3.19)$ & - & - & \multirow{11}{*}{$\begin{array}{c}\mathrm{X}^{2}(\mathrm{df}=19)=42.03, p<0.01 \\
\mathrm{CMIN} / \mathrm{DF}=2,21 \\
\mathrm{CFI}=0.98 ; \mathrm{NFI}=0.97 \\
\mathrm{RMSEA}=0.032(90 \% \mathrm{Cl} \\
0.019 ; 0.045)\end{array}$} & 0.81 & 0.77 & 0.70 & $0.65 ; 0.74$ \\
\hline $\begin{array}{l}\text { Self-efficacy (individual and social } \\
\text { barriers) }\end{array}$ & $12.79(2.39)$ & - & - & & 0.76 & 0.62 & 0.65 & $0.59 ; 0.70$ \\
\hline 2a. Lack of company & $2.58(0.74)$ & 0.46 & - & & 0.73 & & 0.67 & $0.56 ; 0.81$ \\
\hline 2b. Demotivated & $2.46(0.74)$ & 0.47 & - & & 0.74 & & 0.66 & $0.55 ; 0.80$ \\
\hline 2c. Screen access in free-time & $2.63(0.79)$ & 0.54 & - & & 0.74 & & 0.62 & $0.53 ; 0.72$ \\
\hline $\begin{array}{l}2 \mathrm{~d} \text {. Invitation to do other things by } \\
\text { friends }\end{array}$ & $2.56(0.73)$ & 0.49 & - & & 0.73 & & 0.64 & $0.57 ; 0.72$ \\
\hline 2e. Laziness & $2.55(0.81)$ & 0.51 & - & & 0.72 & & 0.54 & $0.48 ; 0.64$ \\
\hline $\begin{array}{l}\text { Self-efficacy (resources to PA } \\
\text { practice) }\end{array}$ & $7.98(2.90)$ & - & - & & 0.64 & 0.65 & 0.65 & $0.59 ; 0.72$ \\
\hline 3a. Lack of PA skills & $2.71(0.75)$ & - & 0.63 & & 0.58 & & 0.70 & $0.59 ; 0.80$ \\
\hline Camtinabk. of PA places near home & $2.69(0.74)$ & - & 0.62 & & 0.56 & & 0.68 & $0.60 ; 0.76$ \\
\hline 3c. Lack of instruction & $2.58(0.74)$ & - & 0.60 & & 0.57 & & 0.64 & $0.57 ; 0.72$ \\
\hline
\end{tabular}


.. continue

\begin{tabular}{|c|c|c|c|c|c|c|c|c|}
\hline \multirow{3}{*}{$\begin{array}{l}\text { Scales ( } n \text { items and } \% \text { of variance } \\
\text { explained by these items) }\end{array}$} & \multirow{3}{*}{ Mean (SD) } & \multicolumn{3}{|c|}{ Validity (Confirmatory Factorial Analysis) } & \multicolumn{4}{|c|}{ Reliability } \\
\hline & & \multicolumn{2}{|c|}{ Factor loading } & \multirow{2}{*}{ Parameters of model fit } & \multirow{2}{*}{$\alpha^{*}$} & \multirow{2}{*}{$\mathrm{CR}$} & \multirow{2}{*}{ ICC } & \multirow{2}{*}{$95 \% \mathrm{Cl}$} \\
\hline & & 1 & 2 & & & & & \\
\hline \multicolumn{9}{|l|}{ Scales of Interpersonal Variables } \\
\hline Support of friends (5 items, $68.3 \%$ ) & $11.46(4.61)$ & - & - & \multirow{6}{*}{$\begin{array}{c}\mathrm{X}^{2}(\mathrm{df}=3)=12.48, p<0.01 \\
\text { CMIN/DF=4.16 } \\
\mathrm{CFI}=0.99 ; \mathrm{NFI}=0.99 \\
\mathrm{RMSEA}=0.052(\mathrm{Cl} \\
90 \%: 0.024 ; 0.083)\end{array}$} & 0.90 & 0.88 & 0.66 & $0.62 ; 0.69$ \\
\hline 4a. Encouragement & $2.20(1.10)$ & 0.76 & - & & 0.88 & & 0.61 & $0.53 ; 0.69$ \\
\hline 4b. PA practice together & $2.49(1.12)$ & 0.85 & - & & 0.87 & & 0.67 & $0.58 ; 0.76$ \\
\hline 4c. Invitation to PA with them & $2.56(1.12)$ & 0.79 & - & & 0.87 & & 0.63 & $0.52 ; 0.71$ \\
\hline 4d. Observation (watching) & $2.16(1.12)$ & 0.77 & - & & 0.88 & & 0.71 & $0.62 ; 0.79$ \\
\hline 4e. Positive comments & $2.04(1.10)$ & 0.70 & - & & 0.87 & & 0.63 & $0.56 ; 0.70$ \\
\hline Support of parents (6 items, $54.6 \%$ ) & $11.08(4.33)$ & & & \multirow{7}{*}{$\begin{array}{c}\mathrm{X}^{2}(\mathrm{df}=7)=21.38, p<0.01 \\
\mathrm{CMIN} / \mathrm{DF}=3.05 \\
\mathrm{CFI}=0.99 ; \mathrm{NFI}=0.99 \\
\mathrm{RMSEA}=0.042(90 \% \mathrm{Cl}: \\
0.022 ; 0.063)\end{array}$} & 0.83 & 0.83 & 0.62 & $0.56 ; 0.65$ \\
\hline 5a. Encouragement & $2.37(1.09)$ & 0.58 & - & & 0.81 & & 0.66 & $0.57 ; 0.74$ \\
\hline 5b. PA practice together & $1.51(0.79)$ & 0.68 & - & & 0.81 & & 0.64 & $0.57 ; 0.72$ \\
\hline 5c. Providing transport to PA & $1.68(0.99)$ & 0.56 & - & & 0.82 & & 0.62 & $0.55 ; 0.70$ \\
\hline 5d. Observation (watching) & $1.59(0.87)$ & 0.69 & - & & 0.80 & & 0.59 & $0.50 ; 0.67$ \\
\hline 5e. Positive comments & $1.89(1.03)$ & 0.82 & - & & 0.78 & & 0.56 & $0.48 ; 0.63$ \\
\hline 5f. Conversation (talking) & $2.03(1.08)$ & 0.69 & - & & 0.78 & & 0.63 & $0.56 ; 0.69$ \\
\hline $\begin{array}{l}\text { Support of the school's teachers ( } 5 \\
\text { items, } 59.3 \% \text { ) }\end{array}$ & $11.10(4.12)$ & - & - & \multirow{6}{*}{$\begin{array}{c}\mathrm{X}^{2}(\mathrm{df}=5)=23.56 \\
\mathrm{p}<0.001 \\
\text { CMIN/DF= } 4.71 \\
\mathrm{CFI}=0.99 ; \mathrm{NFI}=0.98 \\
\mathrm{RMSEA}=0.056(90 \% \mathrm{Cl}: \\
0.035 ; 0.080)\end{array}$} & 0.84 & 0.83 & 0.69 & $0.65 ; 0.73$ \\
\hline 6a. Encouragement & $2.42(1.08)$ & 0.62 & - & & 0.83 & & 0.70 & $0.62 ; 0.77$ \\
\hline 6b. Invitation to PA with them & $2.00(1.08)$ & 0.67 & - & & 0.81 & & 0.66 & $0.58 ; 0.71$ \\
\hline 6c. Supervision (watching) & $2.32(1.09)$ & 0.72 & - & & 0.81 & & 0.64 & $0.55 ; 0.70$ \\
\hline 6d. Positive comments & $2.01(1.02)$ & 0.77 & - & & 0.81 & & 0.67 & $0.58 ; 0.71$ \\
\hline 6e. Conversation (talking) & $2.35(1.09)$ & 0.72 & - & & 0.82 & & 0.61 & $0.53 ; 0.68$ \\
\hline \multicolumn{9}{|c|}{ Scales of Perceived Environment Variables } \\
\hline $\begin{array}{l}\text { Perceived Neighborhood Environ- } \\
\text { ment (PCE) scales regarding engag- } \\
\text { ing in PA (10 items, } 47.6 \% \text { ) }\end{array}$ & $24.52(4.09)$ & - & - & \multirow{13}{*}{$\begin{array}{c}\mathrm{X}^{2}(\mathrm{df}=32)=65.41, \\
\mathrm{p}<0.001 \\
\text { CMIN/DF=2.04 } \\
\text { CFI }=0.98 ; \mathrm{NFI}=0.97 \\
\text { RMSEA }=0.030(90 \% \mathrm{Cl}: \\
0.019 ; 0.040)\end{array}$} & 0.75 & 0.83 & 0.62 & $0.58 ; 0.66$ \\
\hline $\begin{array}{l}\text { PNE (safety and general state of } \\
\text { maintenance) }\end{array}$ & $12.24(2.79)$ & & & & 0.73 & 0.69 & 0.58 & $0.56 ; 0.62$ \\
\hline 7a. Pollution & $2.52(0.85)$ & - & 0.60 & & 0.69 & & 0.64 & $0.57 ; 0.70$ \\
\hline 7b. Condition of sidewalks & $2.55(0.78)$ & - & 0.55 & & 0.70 & & 0.64 & $0.57 ; 0.69$ \\
\hline 7c. Safety for walking & $2.47(0.80)$ & - & 0.54 & & 0.69 & & 0.62 & $0.53 ; 0.69$ \\
\hline 7d. General safety & $2.17(0.85)$ & - & 0.59 & & 0.69 & & 0.57 & $0.49 ; 0.66$ \\
\hline 7e. Safety for cycling & $2.53(0.81)$ & - & 0.48 & & 0.71 & & 0.58 & $0.49 ; 0.66$ \\
\hline PNE (access to PA facilities) & $12.17(2.62)$ & - & - & & 0.78 & 0.74 & 0.67 & $0.64 ; 0.71$ \\
\hline 8a. PA facilities & $2.22(0.82)$ & 0.65 & - & & 0.74 & & 0.65 & $0.59 ; 0.70$ \\
\hline 8b. PA practice by peers & $2.53(0.79)$ & 0.50 & - & & 0.76 & & 0.63 & $0.57 ; 0.70$ \\
\hline 8c. PA places (e.g.,parks) & $2.51(0.85)$ & 0.74 & - & & 0.74 & & 0.61 & $0.56 ; 0.68$ \\
\hline $8 \mathrm{~d}$. Proximity of PA places & $2.44(0.87)$ & 0.62 & - & & 0.75 & & 0.85 & $0.76 ; 0.92$ \\
\hline 8e. General appearance & $2.47(0.80)$ & 0.49 & - & & 0.76 & & 0.64 & $0.58 ; 0.70$ \\
\hline PSE (PA facilities, 3 items, 56.0\%) & $9.87(2.09)$ & & - & \multirow{4}{*}{ Not estimated } & 0.61 & 0.61 & 0.65 & $0.61 ; 0.70$ \\
\hline 9a. PA facilities in free-time & $2.41(0.83)$ & 0.59 & - & & 0.57 & & 0.58 & $0.49 ; 0.66$ \\
\hline 9b. Enjoyable PA facilities & $2.56(0.78)$ & 0.70 & - & & 0.58 & & 0.63 & $0.55 ; 0.71$ \\
\hline 9c. Appearance of PA facilities & $2.13(0.78)$ & 0.46 & - & & 0.60 & & 0.66 & $0.57 ; 0.71$ \\
\hline
\end{tabular}

${ }^{*}$ Cronbach's $\alpha$ was used to represent the internal consistency of the total scale and excluding each item.

$\mathrm{Cl}$ : confidence interval; CMIN/DF: ratio between CMIN (X²) and degree of freedom (df); CR: Composite Reliability; GFI: goodness of fit index; ICC: intraclass correlation coefficient; NFI: non-normed fit index; RMSEA: Steiger's root mean square error of approximation; PA: physical activity; PCE (access): perceived community environment (access to PA facilities); PCE (safety): perceived community environment (safety and general state of maintenance); PSE (PA facilities): perceived school environment (physical activity facilities); PE: Physical Education; SE (social barriers): self-efficacy (individual and social barriers); SE (resources): self-efficacy (resources to physical activity practice). 
A better-fitted model was confirmed with three items in the perceived school environment scale (Figure 1 and Table 2), and three items were excluded (see Supplementary Material 1). The factor loading of the included items ranged from 0.49 to 0.66 .

\section{Construct validity}

There were significant and positive correlations between almost all scales and weekly time in MVPA ( $\mathrm{p}$ < 0.05). The exceptions were the subscale "safety and general state of maintenance", in the perceived neighborhood environment scale (rho $=0.034, \mathrm{p}=0.437$ ) and support of the school's teachers $(\mathrm{rho}=0.013, \mathrm{p}=0.734)$. Other scales had correlations ranging from 0.132 ("individual and social barriers" in self-efficacy) to 0.398 (support of friends, both with $\mathrm{p}<0.01$ ). Most of scale scores showed small correlations with MVPA. These results were similar both in boys and girls in most of the scales. Exceptions included the perceived school environment scale, without significant correlation in girls only $(r h o=0.072, p=0.070)$ and "safety and general state of maintenance" (perceived neighborhood environment scale), with significant correlation in girls only ( $\mathrm{rho}=0.115$, $\mathrm{p}<0.001$, see Table 3).

Table 3. Spearman correlation (rho) between scale scores and weekly time in moderate to vigorous physical activity in the total sample and boys and girls separately. Fortaleza, Brazil (2014).

\begin{tabular}{|c|c|c|c|}
\hline \multirow{2}{*}{ Scales } & \multicolumn{3}{|c|}{$\begin{array}{l}\text { Weekly time in moderate to vigorous PA } \\
\text { (minutes/week) }\end{array}$} \\
\hline & $\begin{array}{c}\text { Total } \\
(\mathrm{n}=1.178)\end{array}$ & $\begin{array}{c}\text { Boys } \\
(n=605)\end{array}$ & Girls $(n=573)$ \\
\hline \multicolumn{4}{|l|}{ Scales of Intrapersonal Variables } \\
\hline Attitude & $0.288^{* *}$ & $0.276^{\star \star}$ & $0.206^{\star *}$ \\
\hline Self-efficacy (individual and social barriers) & $0.132^{* *}$ & $0.155^{\star \star}$ & $0.113^{\star *}$ \\
\hline Self-efficacy (resources to PA practice) & $0.150^{* *}$ & $0.118^{* *}$ & $0.093^{*}$ \\
\hline Total self-efficacy score & $0.200^{* *}$ & $0.117^{* *}$ & $0.161^{* *}$ \\
\hline \multicolumn{4}{|l|}{ Scales of Interpersonal Variables } \\
\hline Support of friends & $0.398^{* *}$ & $0.345^{\star *}$ & $0.219^{\star *}$ \\
\hline Support of parents & $0.239^{* *}$ & $0.218^{* *}$ & $0.182^{\star *}$ \\
\hline Support of the school's teachers & 0.013 & 0.048 & 0.027 \\
\hline \multicolumn{4}{|l|}{ Scales of Perceived Environment Variables } \\
\hline PNE (safety and general state of maintenance) & 0.023 & -0.034 & $0.115^{\star \star}$ \\
\hline PNE (access to PA facilities) & $0.185^{* *}$ & $0.170^{\star *}$ & $0.145^{\star *}$ \\
\hline Total PCE score & $0.154^{* *}$ & $0.090^{*}$ & $0.123^{\star *}$ \\
\hline PSE (PA facilities in school) & $0.114^{* *}$ & $0.092^{*}$ & 0.072 \\
\hline
\end{tabular}

PA: physical activity; PNE: perceived neighborhood environment; PSE: perceived school environment; ${ }^{\star} p<0.05 ;{ }^{* *} p<0.01$.

\section{Internal consistency (reliability) and CF}

Six of the seven scales showed adequate Cronbach's $\alpha$ values $(\geq 0.70)$, ranging from 0.77 to 0.90 , with support of friends being the lower value and perceived neighborhood environment the higher (Table 2). The CF was also higher than 0.70 in these scales. The scale of perceived school environment had $\alpha$ and $\mathrm{CF}$ values of 0.61 . 


\section{Study 2 - Test-retest reproducibility (reliability)}

The ICC ranged from 0.62 (support of parents and perceived neighborhood environment) to 0.70 (self-efficacy, Table 2).

\section{DISCUSSION}

Our results showed that the tested instrument had acceptable validity, internal consistency, and test-retest reproducibility. This instrument can be used in epidemiological studies on PA correlates, impact of intervention on PA and potential mediators among Brazilian secondary students.

\section{Validity}

The scale of attitude was confirmed with all five items of the original instrument ${ }^{5}$. The attitude related to PA is an individual assessment related to overall satisfaction attitude of adolescents about regular PA, considering both positive/negative or instrumental/emotional PA aspects ${ }^{2,5}$. In a socio-ecological theory perspective, attitude is an intrapersonal factor that may be directly associated with PA or be influenced by other aspects such as the PA-related environment ${ }^{4,13}$. However, there is some evidence on the mediating role of attitude in PA interventions among young people ${ }^{4}$, which implies the need for intervention studies that include PA-related attitude in order to evaluate its role in promoting PA in this population.

The self-efficacy scale was confirmed with nine items (one less than the original scale ${ }^{5}$ ) and a bi-factorial structure. Items related to PA barriers, such as tiredness/stress and preference for other activities, were excluded because of high covariance with other items of the self-efficacy scale or low factor loading. Other items on lack of time, adverse weather and fees were also excluded in order to improve the goodness-of-fit of the model in secondary schools. These findings may represent the fact that the perception of barriers and how it influences the self-assessment of ability to practice PA can distinguish between populations. The age range included in studies may also explain distinctions in the structure of items included in PA-related self-efficacy scales ${ }^{2,4}$.

The scales of support of parents and friends for PA were confirmed with acceptable psychometric properties and construct validity with almost all items. One item on friends talking about PA with students was excluded due to the high covariance with the remaining items of the scale, which can be explained because the conversation content (e.g., encouragement, invitation to PA practice) may represent further support for engaging in PA. Previous studies highlighted the fact that support of parents ${ }^{8,9,20}$ and friends $s^{4,6,8,19}$ is an important PA correlate among adolescents. However, insufficient information on the validity and reliability of scales for measuring these variables is usual, which makes it difficult determine the real understanding of the relationship between PA and these aspects, as well as how interventions can modify these aspects ${ }^{9}$.

Our results showed that the scale regarding support of the school's teachers had adequate psychometric properties. Similarly, Ommundsen 
et al. ${ }^{7}$ conducted a high methodological quality study ${ }^{8}$ aiming to validate PA-related variable scales among students from four European countries and identified the importance of support of the school's teachers (e.g., talk about exercises in classes) as an interpersonal factor of PA practice. Yildirim et al. ${ }^{15}$ also found that support of the school's teachers is an important mediator of the changes in PA during recess. In our study, the scores of this scale did not have a significant correlation with MVPA, probably because we measured total MVPA and not PA within the school only ${ }^{3}$. However, the scores of the scale regarding support of the school's teachers had significant correlations with support of parents, support of friends, attitude and perceived school environment (rho coefficient of 0.149, 0.182, 0.105 , and 0.185 , respectively, all with $\mathrm{p}<0.01$, data not shown in tables). Thus, measuring this PA-related factor may be important for indicating the focus of interventions within the school setting and variables that can explain PA practice in students.

The structure of perceived neighborhood environment scale consisted of two factors, which was different than the original instrument ${ }^{5}$. After we tested this scale in an exploratory factor analysis, the confirmatory analysis showed a better-fitted model with the items related to safety and general state of maintenance of the neighborhood in a single factor. Additionally, four items were excluded from the perceived neighborhood environment scale (items related to sidewalks, bike paths, and safety/satisfaction with the PA places). This distinction in the structure of scales of PA-related environment variables among adolescents is common because there are environment distinctions between sites and they can vary in the interactions with the stimulus in PA practice ${ }^{8}$. In our study, the subscale of "safety and general state of maintenance" did not have a significant correlation with MVPA in the total sample and in boys. A non-significant correlation between PA-related environment scales and PA practice was also found in the validation study of the Neighborhood Environment Walkability Scale for Youth (NEWS-Y) among American adolescents ${ }^{10}$. These results can be explained because the relationship between some environmental attributes and PA can be more consistent with specific PA types (e.g., PA for travelling $)^{20}$. This reinforces the importance of evaluating other environmental contexts that may be related to PA among young people, such as the school environment ${ }^{2,10,19}$.

The scale of perceived school environment had a better-fitted model and acceptable psychometric properties with three items and a significant (but small) correlation with MVPA. Other items were excluded because they had low factor loading and probably measured other constructs of the school environment related to PA. Measuring the student's perception of the school environment related to PA is difficult because there are different aspects of the school environment that can be related to PA. Stanley et al. ${ }^{3}$ evaluated a scale with nine items on the perceived school environment, but only $52.8 \%$ of the variance of this construct was explained by these items. Yildirim et al. ${ }^{15}$ showed a positive association between perceived school 
environment and PA measured using accelerometers during the school breaks, but only in girls. Thus, the validation of PA-related perceived school environment needs further investigation. The scale validated in the present study may assist in studies of the PA facilities in school and how they contribute to the PA practice, which may indicate an important focus for PA public policies among young people ${ }^{13}$.

\section{Reliability}

Most scales had adequate internal consistency and reliability ( $\alpha$ and CF higher than 0.70). However, the scale of PA facilities in school (perceived school environment) had substantial internal consistency and reliability ( $\alpha$ and CF 0.61), which may be explained due to the low number of items ${ }^{2,14}$. Moreover, all scales had substantial test-retest reproducibility (ICC ranging from 0.62 to 0.70 ). A systematic review on reliability of scales of potential PA mediators in young people found 68 studies with $\alpha$ ranging from 0.30 to 0.92 , with values higher than 0.60 on only 24 occasions $^{2}$. Stanley et al. ${ }^{3}$ evaluated an instrument with intrapersonal, interpersonal and environmental scales of factors associated with PA and found $\alpha$ and ICC lower than 0.50 for scales such as PA-related support of teachers and access to PA resources in school. Low reliability was also highlighted in other scales of PA-related perceived environment ${ }^{7,8,10}$ and social support ${ }^{6,7,9}$. These aspects indicate the complexity of measuring the youths' perception of factors associated with PA due to seasonal changes in these factors over a short time, as well as the difficulties of adequately describing the structures (e.g., PA facilities) and components (PA behavior of their parents) related to $\mathrm{PA}^{8}$.

\section{Strengths and limitations}

This study contributes to the literature by presenting a valid and reliable instrument with scales focused on identifying different intrapersonal, interpersonal and environmental factors associated with PA in secondary schools. The inclusion of school-related scales (support of the school's teachers and perceived school environment) is also an important aspect of this study. Finally, the sample with sufficient statistical power and the different statistical procedures used to make inferences, both for the analysis of validity as to the reliability of instrument ${ }^{14}$, were other strengths of this study.

Our study also had limitations. All scales had only substantial test-retest reproducibility, which is expected on scales used with young people. Also, the scale of perceived school environment was confirmed with only three items, making it impossible to measure the goodness-of-fit of the model. Measuring the students' perception of the school environment related to PA has been one of the difficulties in studies on potential PA mediators among young people ${ }^{8}$. Differences between the samples of the present study in PA level and the use of self-reported PA were limitation that can have a negative impact on some conclusions, such as the validity and reproducibility parameters of the instrument. Finally, the study did 
not include students from grade 6 or those attending private schools. Thus, the extrapolation of the findings to other populations is limited.

\section{CONCLUSION}

The instrument tested in this study showed acceptable validity and reliability and can be used to measure different intrapersonal (attitude and self-efficacy), interpersonal (social support of parents, friends, and the school's teachers) and environmental (perceived neighborhood and school environment) factors related to PA in secondary students. Health professionals, researchers, and managers of PA promotion public policies may consider the use of this instrument to identify factors associated with PA in secondary students, as well as the mediators of the impact of PA promotion interventions in this population.

\section{Acknowledgements}

We thank the Municipal Education Department for technical support and authorization to the study execution. We thank all members of the school community (managers, teachers, parents and students), as well as all members of the "Fortaleça sua Saúde" Working Group, who were involved in this study.

\section{REFERENCES}

1. Bauman AE, Reis RS, Sallis JF, Wells JC, Loos RJ, Martin BW, et al. Correlates of physical activity: why are some people physically active and others not? Lancet 2012;380(9838):258-71.

2. Brown H, Hume C, ChinAPaw M. Validity and reliability of instruments to assess potential mediators of children's physical activity: A systematic review. J Sci Med Sport 2009;12(5):539-48.

3. Stanley RM, Ridley K, Olds TS, Dollman J. Development and psychometric properties of the Y-PASS questionnaire to assess correlates of lunchtime and after-school physical activity in children. BMC Public Health 2014;14(1):412.

4. Van Stralen MM, Yildirim M, Velde ST, Brug J, van Mechelen W, Chinapaw MJ, et al. What works in school-based energy balance behaviour interventions and what does not: A systematic review of mediating mechanisms. Int J Obes 2011;35(10):1251-65.

5. Farias Júnior JC, Lopes AS, Reis RS, Nascimento JV, Borgatto AF, Hallal, PC. Development and validation of a questionnaire measuring factors associated with physical activity in adolescents. Rev Bras Saúde Matern Infant 2011;11(3):301-12.

6. Huang Y-J, Wong SH, Salmon J, Hui SS. Reliability and validity of psychosocial and environmental correlates measures of physical activity and screen-based behaviors among Chinese children in Hong Kong. Int J Behav Nutr Phys Act 2011;8(1):16 .

7. Ommundsen Y, Page A, Ku P-W, Cooper AR. Cross-cultural, age and gender validation of a computerised questionnaire measuring personal, social and environmental associations with children's physical activity: the European Youth Heart Study. Int J Behav Nutr Phys Act 2008;5(1):29.

8. Reimers AK, Mess F, Bucksch J, Jekauc D, Woll A. Systematic review on measurement properties of questionnaires assessing the neighbourhood environment in the context of youth physical activity behaviour. BMC Public Health 2013;13(1):461. 
9. Trost SG, McDonald S, Cohen A. Measurement of general and specific approaches to physical activity parenting: A systematic review. Child Obes 2013;9(s1):40-50.

10. Rosenberg D, Ding D, Sallis JF, Kerr J, Norman GJ, Durant N, et al. Neighborhood Environment Walkability Scale for Youth (NEWS-Y): reliability and relationship with physical activity. Prev Med 2009;49(2):213-8.

11. Saunders RP, Pate RR, Felton G, Dowda M, Weinrich MC, Ward DS, et al. Development of questionnaires to measure psychosocial influences on children's physical activity. Prev Med 1997;26(2):241-47.

12. Brasil, Ministério da Saúde. Política Nacional de Promoção da Saúde. Brasília: MS; 2010.

13. Ferreira I, Van Der Horst K, Wendel-Vos W, Kremers S, van Lenthe FJ, Brug J. Environmental correlates of physical activity in youth-a review and update. Obes Rev 2007;8(2):129-54.

14. Hair JF, Black WC, Babin BJ, Anderson RE, Tatham RL. Análise multivariada de dados. São Paulo: Bookman; 2009.

15. Yildırım M, Arundell L, Cerin E, Carson V, Brown H, Crawford D, et al. What helps children to move more at school recess and lunchtime? Mid-intervention results from Transform-Us! cluster-randomised controlled trial. Br J Sports Med 2013;48(3):271-7.

16. Associação Brasileira das Empresas de Pesquisa: Critério de classificação econômica Brasil. In. São Paulo: ABEP; 2008.

17. Farias Júnior JC, Lopes AS, Mota J, Santos MP, Ribeiro JC, Hallal PC. Validade e reprodutibilidade de um questionário para medida de atividade física em adolescentes: uma adaptação do self-administered physical activity checklist. Rev Bras Epidemiol 2012;15(1):198-210.

18. Kline RB. Principles and Practice of Structural Equation Modeling. 2011 (3 ed.). New York: Guilford. 2011.

19. Dewar DL, Lubans DR, Plotnikoff RC, Morgan PJ.Development and evaluation of social cognitive measures related to adolescent dietary behaviors. Int J Behav Nutr Phys Act 2012;9:36.

20. Reimers AK, Jekauc D, Mess F, Mewes N, Woll A. Validity and reliability of a self-report instrument to assess social support and physical environmental correlates of physical activity in adolescents. BMC Public Health 2012;12:705.
CORRESPONDING AUTHOR

Valter Cordeiro Barbosa Filho Universidade Federal de Santa Catarina

Centro de Desportos, Departamento de Educação Física

Campus Universitário - Trindade. 88040-900, Florianópolis, SC, Brasil.

E-mail: valtercbf@gmail.com 